\title{
Meaningfulness as Sensefulness
}

\section{Joshua Lewis Thomas ${ }^{1}$}

Received: 13 March 2018 / Revised: 26 December 2018 / Accepted: 18 February 2019 /

Published online: 26 February 2019

(C) The Author(s) 2019

\begin{abstract}
It is only in the last few decades that analytic philosophers in particular have begun to pay any serious attention to the topic of life's meaning. Such philosophers, however, do not usually attempt to answer or analyse the traditional question 'What is the meaning of life?', but rather the subtly different question 'What makes a life meaningful?' and it is generally assumed that the latter can be discussed independently of the former. Nevertheless, this paper will argue that the two questions are indeed connected, and that identifying and expanding upon the most plausible analysis of the former will provide the resources necessary to determine the most plausible answer to the latter. Specifically, this paper will argue that the traditional question is simply a request for the information which constitutes a coherent answer to one or more of a certain set of questions regarding human existence that were salient to the asker. In simpler language, the meaning of life itself is the information a person needs to make sense of it. This analysis can then also be applied to individual lives, such that asking for the meaning of $\mathrm{X}$ 's life is an analogous request for the information necessary to make sense of that life in particular. Running with this concept of the 'meaning' of something as its 'sense', the paper then outlines an accompanying theory of 'meaningfulness' as 'sensefulness': a measure of the richness of certain aspects of the life, multiplied by their intelligibility.
\end{abstract}

Keywords Meaning $\cdot$ Meaningfulness $\cdot$ Life $\cdot$ Sense $\cdot$ Coherence $\cdot$ Intelligibility

\section{Introduction}

The traditional question 'What is the meaning of life?' has often been seen as philosophy's central concern, at least by those outside of the profession. ${ }^{1}$ Despite this,

${ }^{1}$ And perhaps a few within the profession too. See Tartaglia (2016) for one example.

Joshua Lewis Thomas

joshlewisthomas@hotmail.co.uk; joshua.thomas@open.ac.uk

1 School of Politics, Philosophy, Economics, Development, Geography, The Open University,

Walton Hall, Milton Keynes MK7 6AA, UK 
it is only in the last few decades that analytic philosophers in particular have begun to pay any serious attention to the topic. Such philosophers, however, do not usually attempt to answer or analyse the question above, but rather the subtly different question 'What makes a life meaningful?' where it is generally assumed that these subjects can be tackled independently. ${ }^{2}$ Typically, the thought is that the former is asking a question about the origins of all life or for some clue regarding the purpose or nature of existence itself, whereas the latter is seen as asking a narrower question about a property which individual lives may possess - specifically, a property which is seen as being valuable or desirable and has something to do with, for instance, how much a life matters or whether it is connected to some worthy goal. ${ }^{3}$

Nevertheless, this paper will argue that the two questions are indeed connected, as is indicated by the similar terminology being used (i.e. 'meaning' and 'meaningfulness'), and that identifying and expanding upon the most plausible analysis to the former will provide the resources necessary to determine the most plausible answer to the latter. In other words, once we clear up what is meant by the traditional question 'What is the meaning of life?', and the concept of 'meaning' in a more general sense, we will be able to find our way to a straightforward and credible analysis of the concept of 'meaningfulness' and the criteria for its application to individual lives.

Specifically, sections 2 and 3 of this paper will argue, taking inspiration from Joshua Seachris (2009), that the traditional question is simply a request for a coherent answer to one or more of a certain set of questions regarding human life that were salient to the asker. In simpler language, the meaning of life itself is the information a person needs to make sense of it with regard to features such as its origin, purpose, and impact. This analysis can then also be applied to individual lives, such that asking for the meaning of X's life is an analogous request for the information necessary to make sense of that life in particular. Running with this concept of the 'meaning' of something as its 'sense', section 4 will then outline an accompanying theory of 'meaningfulness' as 'sensefulness': a measure of the richness of certain features of the life, multiplied by their intelligibility. Finally, section 5 will contain some concluding remarks and highlight the strengths of my overall account relative to theories of meaningfulness found in the existing literature.

\section{Meaning as Sense}

My aim in this paper is to give an analysis of the concept of meaningfulness and the question 'What is the meaning of life?' which is unified, congruent with our everyday language use, and intuitively plausible. To show how this can be done, I will first outline Seachris' analysis of the traditional meaning of life question (2009). Often, this question is seen as somehow very opaque or mysterious, and not admitting of any straightforward answer or even interpretation. Nevertheless, Seachris argues there does exist a very natural reading of this question. In essence, his theory is this: when we ask, 'What is the meaning of life?' what we are really

\footnotetext{
${ }^{2}$ See Tartaglia (2015) for a critique of this common practice. Philosophers who have departed from this trend and attempted to discuss the more traditional question include Seachris (2009) and Cottingham (2003).

${ }^{3}$ These two questions are sometimes referred to as the meaning of life question and the meaning in life question (e.g. Schinkel et al. 2015, p.4). However, the in/of distinction can be interpreted in different ways, so I will refrain from using it here.
} 
requesting is specifically "a narrative that narrates across an existentially relevant threshold of life phenomena and questions" (p.18).

To explain, let's imagine I walk into my office and, finding a stranger sitting in my chair, I ask, "What is the meaning of this?"4 Now in such a case it seems that my request is nothing mysterious; I am merely asking for "an explanation as an interpretive framework through which to view the event" (p.13). This will involve me learning certain facts, such as the causal path which led to the stranger's presence, or their intentions, and from these facts I will be able to develop a narrative through which I can make sense of the event. Seachris claims that when we ask for the meaning of something, we are simply asking for the story of it (p.13). To be clear though, what the asker is ultimately after here is a way to make sense of the event, but Seachris believes we typically accomplish this through the use of narratives (p.11).

Aside from the connection between narratives and sense-making, ${ }^{5}$ the important conclusion to draw from Seachris' analogy is that, when someone asks for the meaning of life, we can interpret this request in precisely the same straightforward way as we do in the case of the stranger: as asking for some explanation, potentially in narrative form, that will render the event intelligible to us. The only difference is that what we want to make sense of in this case is not the presence of a stranger in my office, but rather the phenomenon of human existence itself. As Seachris explains, "we lack important parts of the story... and we desire to fill the existentially relevant informational gaps in our understanding of the universe we inhabit" (p.13). This goes some way towards explaining why we might expect the answer to the traditional question to take the structure of a 'pithy formula', since all we might plausibly require are a few key facts to complete the existential narrative we are trying to build in order to make sense of 'life'. 6

Granting all this, Seachris asserts that the meaning of life will simply be whatever true narrative successfully narrates over "those areas of greatest existential import to humans" (p.13). Essentially, it would be a story about existence which truthfully answers certain weighty questions we have about life. Seachris provides a list which he claims 'more or less composes' this set of questions:

i. "Why does anything or we or I exist at all?"

ii. "Does life have any purpose(s), and if so, what is its nature and source?"

iii. "Does the worth and value of (our) pursuits and projects need grounding in something else, and if so, what?"

iv. "Pain and suffering are part of the universe... Why?"

v. "How does it all end? Is death final? Is there an eschatological remedy to the ills of this world?" (p.14)

I agree with the core of what Seachris claims here; his account has the power to unify the diverse interpretations of the 'meaning of life' question into just one straightforward request, thereby vindicating our complex intuitions about the nature of meaning. For instance, to ask about the meaning of life can be to ask about the aims, origin, and

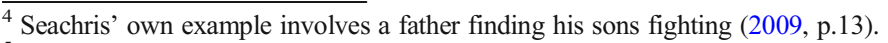

${ }^{5}$ Which is also noted by many other theorists, such as Strawson (2004, p.439), Velleman (2003, p.1), Vice (2003, p.95), and Heyd and Miller (2010, p.23).

${ }^{6}$ Bennett (1984, p.589) and Thomson (2003, p.5) each note the intuition that 'the meaning of life' could be provided as some kind of 'simple formula'.
} 
nature of life, all at once, without that request being confused. Moreover, his analysis interprets the traditional question "on its own linguistic terms" (p.17) - asking about the meaning of life is just like asking about the meaning of any event - and thereby aligns with an everyday use of the term 'meaning'. Finally, I believe Seachris' account can also be modified and expanded to provide an analysis of both '(a) meaning' and 'meaningfulness' - which I see as subtly different notions - as well as sets of requirements which both individual lives and life in general must fulfil if they are to be appropriately described as having 'a meaning' or being 'meaningful'. Nevertheless, before I build on this theory further in section 3 , it would first be useful to provide additional context and clarification regarding the general concept of meaning which I will defend here.

Though this is not always made transparent, the term 'meaning' is used both in a discrete noun form (e.g. a meaning, the meaning, or meanings), identifying some specific feature of a thing, and in a continuous noun form (simply: meaning), perhaps identifying the presence or amount of some individual meanings. ${ }^{7}$ Simply put, I propose we interpret 'meaning' (in its continuous noun form) as being equivalent to 'sense'. Hence ' $a$ meaning' would be equivalent to ' $a$ sense' and 'meanings' to 'senses' etc. On this analysis, when someone asks, 'What is the meaning of life?' they are essentially asking 'What is the sense of life?' When someone worries that life is meaningless, they are essentially worrying that it is senseless. And, as I shall argue later, when someone desires a life which is meaningful, they are essentially hoping for a life which is sense-full or full-of-sense.

The identification of meaning and sense is uncontroversial in linguistics. For instance, consider how a word's 'meaning' is also its 'sense' and the synonymous use of 'nonsense' and 'meaningless' to describe an incoherent utterance. However, I'm suggesting that this identity between meaning and sense extends even to discussions about the existential meaning of life. Several philosophers have noted this possibility but, to my knowledge, none have explored it in any detail besides Seachris (2009) and Thomson (2003). ${ }^{8}$ One motivation for positing this conceptual relationship, which I have already discussed, is the undeniable similarity between the questions 'What is the meaning of life?' and 'What is the meaning of this?', where the latter transparently uses 'the meaning' to mean 'the sense'. Do we have any good reason for thinking that the existential question does not use 'meaning' in the same way? In the final section of this paper I will consider some rival theories of meaning but, for now, I will set out some reasons which go a long way towards confirming that 'meaning', in existential contexts, is being used in the same way, and that existential meaning simply is sense.

First of all, if we take a brief survey of the way a few other languages refer to 'the meaning of life', we can see that this lends weighty support to my analysis, given the concept of 'sense' is right at the forefront of each translation of the term 'meaning': e.g. 'el sentido de la vida' (Spanish), 'le sens de la vie' (French), 'der Sinn des Lebens' (German), 'il senso della vita' (Italian). If the English term 'meaning' had different uses in everyday/linguistic and existential contexts, then we would expect translations of the latter to reflect that. However, as we can see,

\footnotetext{
${ }^{7}$ As I will demonstrate, the term 'meaningfulness' is more closely connected with the continuous noun form, since it is a measure of the quantity and quality of meaning associated with something.

${ }^{8}$ For instance, Audi (2005, p.333), Cottingham (2003, p.22), White (2009, p.425), and Veal (2017, p.251-2).
} 
sense seems to be the primary translation of existential 'meaning', indicating that the English term can be interpreted as 'sense' in both contexts.

This conceptual connection, if not identity, between existential meaning and sense is also supported by a host of psychological analyses of meaning in life. For instance, Markman, Proulx, and Lindberg write that "all accounts of meaning converge at sense making" $\left(2013\right.$, p.4). ${ }^{10}$ As evidence for this, there are various studies which seem to demonstrate a relationship between existential meaning and our perception that things in our environment are intelligible or coherent. For instance, one study showed that an experience of random or senseless patterns lowered participants self-reported perceptions that their own lives were meaningful (Heintzelman et al. 2013). Whilst another showed that participants in conditions designed to make them feel life was less meaningful (forced to read Kafka etc.) became much more motivated and successful at an arbitrary pattern recognition test (e.g. Proulx and Heine 2009). ${ }^{11}$ The offered explanation for this was that we have a drive to find meaning in the world, especially when we are confronted with meaninglessness. However, this explanation only works if there is a conceptual identity or at least close relationship between meaning and coherence or intelligibility, i.e. sense.

Psychologists working in this area have also provided a great deal of detail as to the precise nature and function of meaning/sense in our cognitive processes. The basic idea is that, evolutionarily, our survival depends on our ability to detect patterns and relationships in our environment and make use of this knowledge to plan our behaviour. ${ }^{12}$ We do this by forming what are called 'meaning-frameworks', which are mental representations or schematics of actual and expected connections between various things in our world. Proulx and Heine explain:

"These mental representations encompass anything that one might expect to be related to anything else - people, places, objects, events - in any way that they could be construed as related - causally, spatial- temporally, teleologically. When individuals encounter something, anything, that is not currently related to an existing framework of relations, it said to be meaningless; it only becomes meaningful once a relationship, any manner of relationship, is discovered or imposed." (2006, p.310)

In short, "Meaning frameworks are the complex web of propositions that we hold about how things are in the world and how things will be" (George and Park 2016, p.206).

Psychologically speaking, we can understand these meaning-frameworks as being constituted by sense or meaning (in its continuous noun form) or rather a multitude of interconnected meanings (in its discrete noun form). Each connection is itself $a$

\footnotetext{
${ }^{9}$ Another minor piece of linguistic evidence is that the word 'meaning' comes from the Old High German word 'meinen', which means 'to have in mind', indicating, at the very least, the cognitive roots of the concept (Martela and Steger 2016, p.537).

${ }^{10}$ Further examples include Juhl and Routledge who write that "meaning can refer to feelings that the world outside of the self makes sense" (2013, p.220) and Stillman and Lambert who report that "By meaning of life... people typically intend not a dictionary definition of life - but rather a way to make sense of their existence" (2013, p.306). For many more examples see Hicks and Routledge (2013).

${ }^{11}$ Importantly, in both studies, positive or negative affect was reported not to have played any role in producing these effects (Heintzelman and King 2014, p.156).

${ }^{12}$ See, for example, George and Park (2016, p.210), and Heintzelman and King (2014, p.155).
} 
meaning and we can build up these connections or meanings in order to develop a picture of our world and how it works. For instance, if I piece together that fire causes smoke, can be caused by lightning, and can be used to cook food, then I have learned three meanings of fire - three ways the phenomenon of fire can be connected to other things via, respectively, its effects, origin, and use. I will discuss these sorts of connections in more detail shortly but, for now, note how natural it is to remark, for example, fire means smoke, fire means lightning has struck, or fire means we can cook our dinner. It is also worth noting that meaning-connections such as these are capable of being more or less robust, depending on the closeness, reliability, and strength of these relationships, and that these meanings are capable of being identified on a relatively basic, fundamental level (e.g. lightning strike $\mathrm{x}$ caused tree $\mathrm{y}$ to burn down) or on a higher-order level made up of a multitude of interconnected basic meanings (e.g. lightning strike $\mathrm{x}$ caused the collapse of ecosystem $\mathrm{z}$ by initiating a devastating forest fire which spread from tree to tree and killed many animals etc.).

Our overall meaning-framework or sense-framework is what allows us to understand our world. New events or phenomena will be experienced as intelligible by us to the extent we are capable of grasping their internal structure (if they are complex) and connections to the world around them (such as causes and effects), and to the extent this newly perceived web of meanings can be added to our pre-existing meaning-framework without causing conflicts or inconsistencies. When we 'make sense' of something we observe, we are quite straightforwardly turning our perceptions into sense, by building new structures into our existing frameworks of meaning/sense. Moreover, the more meanings of something I grasp and can bring into line with this pre-existing meaning-framework, the more meaning or sense (in their continuous noun forms) that phenomenon or event will have for me.

Once this system and drive for comprehending our world was established, it was only natural that it should be applied to more complex and abstract things as our mental capacity developed over time (Proulx and Heine 2006, p.311). As Martela and Steger put it: "Beginning at the discrete level of moment-to-moment experiences... it would appear that ever more elaborate models of patterns and predictability can be constructed, eventually building to overarching meaning models that help people make sense of one's self, the world, and one's fit within the world" (2016, p.533). Thus, it is this basic drive and capacity for detecting and recording patterns and relationships in our environment which, when directed at the phenomenon of life itself, provokes the existential question about life's meaning with which we are now familiar. ${ }^{13}$ We don't just want to know the meanings of events and phenomena in our lives, we want to know what meanings are held by each of our lives as wholes and by life altogether. In other words, we want to be able to make sense of these things by finding out how they connect up to the rest of reality in certain salient ways.

\footnotetext{
${ }^{13}$ Heintzelman et al., for instance, write that "The oft-noted human need for meaning can be located in this primal drive for detecting the regularities of existence" $(2013$, p.96). Similar accounts can be found in Proulx and Heine (2006, p.311) and Heine et al. (2006, p.91). If true, this would go some way towards explaining why a drive for meaning is sometimes characterised as "the primary motivation force in man" (Frankl 1946, p.99). It isn't merely some shallow, modern predilection; it is fuelled by one of our most fundamental impulses.
} 


\section{The Meaning of Life (and $a$ Life)}

Recall Seachris' theory that 'the' meaning of life is the true narrative which answers a list of various existentially weighty questions. I believe that Seachris' core insight can be reconciled with the above psychology-informed analysis of meaning as sense. However, some amendments need to be made. Summarising much of the above discussion, Martela and Steger write that, "When we ask what something means, we are trying to locate that something within our web of mental representations. Meaning is about mentally connecting things. This is true whether we ask about the meaning of a thing or the meaning of our life" (2016, p.537). We can thus interpret Seacrhis' list of meaning-questions as targeting an especially salient assortment of these connections between life and the rest of reality which have some existential importance to us but are, as of yet, arguably unknown. When we ask about the meaning of life, we are hoping to make better sense of it by discovering more about what these particular important meaning-connections are.

Nevertheless, I think Seachris is wrong, first off, to suggest that what counts as 'the' meaning of life must be a narrative which narrates across all the above questions. It is closer to how we naturally use the term, and more in-keeping with my analysis above, to say that 'the' meaning of life could be smaller pieces of this narrative, answering only a subset (or even just one) of these questions. Assuming, for now, that Seachris has identified the right questions, we should instead suggest that answers to any of these questions (i.e. any of these connections between life and reality) could constitute $a$ meaning of life. Consequently, life will have multiple meanings. Yet, we can stipulate one or more of them as the meaning of life in different contexts depending on our concerns. For instance, remembering that to ask about the meaning of life is to make a request that it be rendered comprehensible to us, the information that is required for this task will depend on the knowledge we already have and which areas of our ignorance we care to address. For someone who knows nothing and cares about everything, the full answer to their request - and hence 'the' meaning of life - might well be the entire narrative. Alternatively, if the only thing I'm confused about is where we came from, then an explanation of the origin of life alone may be all I need to perceive life as making sense, and so that is all I need to be provided when I ask about 'the' meaning of life. In short, it seems precisely which piece of information/connection(s) counts as the meaning of life will be relative to different individuals (or groups of individuals with similar knowledge and concerns).

My second objection to Seachris' theory is that his list of meaning-questions is not entirely fitting; iii, iv, and v, for instance, while potentially very significant questions, do not strike me as the kinds of things we are primarily targeting when we talk about the meaning of life. The traditional question, it seems to me, would not be appropriately answered with story about meta-ethics (iii), a theodicy (iv) or a description of the decomposition of human bodies (v). Neither can some of these questions, in the complex, nuanced, and multi-part way he has worded them, be given answers in terms fully reducible to the kinds of basic connections which appear to make up our meaningframeworks. Recall that these fundamental meaning-connections were most naturally identified as, for instance, very straightforward causal or teleological relationships. We might therefore expect the final meanings of some event to be stateable in terms of these kinds of basic relationships, whether on an atomic or higher-order level, but the answers to some of Seachris' questions cannot be. Moreover, some these questions 
seem to target only limited aspects of life (e.g. suffering, mortality) rather than life itself. The answers to Seachris' questions might help us make sense of certain features of life then, but they don't all seem fittingly described as meanings-of-life. Granting that, I would like to repopulate this list of questions with my own slightly more systematically developed suggestions. ${ }^{14}$

To be clear, I have argued that the answers to certain questions about life will naturally strike us as life's meanings, but that Seachris has mis-identified these questions. What are the right questions? From the above psychological analysis, it appears we could identify any of the connections which contribute to our meaning-frameworks as potential meanings of an event, and hence we should simply look for the sorts of questions which target those kinds of connections. Nevertheless, some of the connections suggested (e.g. spatial and temporal) don't seem naturally labelled as 'meanings' of things in ordinary language. In what follows, I aim to highlight a few of the connections which do carry over to everyday meaning-talk, and the questions which target them, i.e. the kinds of questions can be answered to intuitively give the meanings of ordinary events, and hence could be used to indicate life's potential meanings.

First, to make things more straightforward, we can imagine a simple and nonagential event, like a bolt of lightning. If someone saw this lightning and asked, 'What is the meaning of this?', it seems to me that there are two things we could reply to her. Firstly, we could give her an explanation (or narrative) of the causal path which results in lightning strikes. Secondly, we could tell her the kinds of things that typically result from lightning strikes, or the specific things which are likely to result from this lightning strike (e.g. if it will burn the house down or not). This gives us the first two questions to which the answers might intuitively be the meaning of some event $\mathrm{x}^{15}$ :

1. What caused $\mathrm{x}$ to happen?

2. What resulted from $x$ ?

Next, we can imagine an action rather than event, to see what this adds. For an action, such as a stranger seating himself in my office, it does seem that either of the first two questions could be answered to give the action's meaning, but there is another question that is perhaps even more salient in this case:

\section{What were the Agent's intentions in doing $\mathrm{x}$ ?}

Here, the agent explaining the purposes or intentions behind their action (e.g. 'I needed to meet with you') again seems like an appropriate response to the question 'What is the meaning of this?' when it is directed at the stranger's presence. ${ }^{16}$

The varieties of meaning identified so far are thus constituted by teleological connections, or forward and backward-looking causal connections. However, the next meaning-question we can identify does not target a distinct new type of ground-level meaning-connection, but rather a combination of these first few types of meaning held

\footnotetext{
${ }_{14}$ Although two of my suggestions (1 and 3) will overlap largely with Seachris' $i$ and ii.

15 Both of these kinds of meanings (along with 3) are what Grice refers to as 'natural' meaning (1957, p.378).

16 Thomson, in his discussion of the 'hermeneutic' meaning of a life, also talks about how an action can have a meaning in terms of having a purpose (2003, p.140).
} 
together in one higher-order structure. Specifically, if we imagine an action or event that takes place on a longer scale with more internal complexity, such as a flurry of moves in a chess game, and a person asks, 'What was the meaning of that?', the reply they may well get is simply a story of the moves. In other words, a recounting of the events in the order they happened, but with their most central and revealing causal and teleological connections highlighted (e.g. 'Bill moved his king because Andrea had put him in check, and then...'). This gives us another question that might be added to our list, primarily for events or sequences of events which are internally complicated and might defy understanding for that reason.

\section{What was $\mathrm{x}$ ? /What was the story of $\mathrm{x}$ ?}

As noted, strictly speaking, the answer to this question does not constitute a new ground-level kind of meaning; it asks about the various causal/teleological meanings or connections within some extended event rather than about some new kind of connection between that event and other things. Nevertheless, because it can sometimes feel natural to identify both these external and selected internal connections of an event as its meanings in ordinary language, it is reasonable and fruitful to proceed as if this fourth question identifies a fourth distinct kind of meaning. Furthermore, as noted above, the other external kinds of meaning discussed so far can also sometimes operate at a higher-order level (e.g. a causal origin meaning built out of many smaller, atomic meaning-connections), so in some ways the distinction disappears. ${ }^{17}$

Finally, there is one kind of meaning which can belong to a certain subset of events: communicative actions. By this I mean things like utterances, writings, and gestures: anything which one can interpret as intentionally attempting to convey a message. For these examples, the answer to 'What is the meaning of $x$ ?' can be whatever assertion, command, question etc. was being signified. ${ }^{18}$ This gives us the fifth and final meaning-question:

\section{What does x signify?}

There may be some forms of meaning which I have missed - indeed, according to the psychological analysis of meaning, there will perhaps be many more varieties of basic connection which contribute to our meaning-frameworks - nevertheless, the ones I have identified seem to be amongst those most naturally described, in our everyday language, as the 'meanings' which ordinary events can have. For ease, I will label them, respectively, 'origin-meaning', 'impact-meaning', 'purpose-meaning', 'narrativemeaning', and 'communicative-meaning'. Simple non-agential events could have the first two kinds of meaning, while complex, agential, and communicative events could potentially possess all five kinds of meaning. For instance, take a particular production of the play Hamlet. If my friend turns to me at the end and asks me "What was the

\footnotetext{
${ }^{17}$ The legitimacy of higher-order meanings must be granted in general because, as we shall see, meaningfulness only really appears with regard to meanings which are themselves full-of-meaning in this way.

18 This is what Grice would call 'nonnatural' meaning (1957, p.378). Thomson's own hermeneutic theory focuses on this kind of meaning. For instance, he claims that "Knowing the meanings of one's life can be understood as knowing how to interpret it as one would a text" (2003, p.150). I think this strays too far from our usual concerns about the meaning of life, however, as I explain below.
} 
meaning of that?' There are (at least) five sorts of answers I could appropriately give him, and which one is most fitting will depend on which of the above questions was most salient to him at the time of asking.

Most likely he could have been asking me for the moral or message of the play, i.e. its communicative-meaning. ${ }^{19}$ This answer would thus be the meaning of the play that my friend was seeking. Alternatively, he could be expressing some confusion as to the actual plot of the play. In this case, the meaning of the play he is requesting is a recounting of its story, i.e. it's narrative-meaning. The other three interpretations are likely to be less salient for this situation, but can still be brought forth. For instance (taking the play as a single action, perhaps belonging to the director), let's say the director is known for outlandish experimental theatre, and that my friend is confused as to why he chose to put on such a mediocre and by-the-books version of Hamlet. In this case, my friend's request for the meaning of the play could be interpreted as a request for the purpose-meaning of the action: 'Why did the director choose to do this?' We could also interpret his question as asking for the impact-meaning of this action: 'What will this do to the director's career now?' Or finally even as a request for the causes that produced the action, i.e. its origin-meaning: 'What on earth led to this?'

To reiterate, when a person asks, 'What is the meaning of this?', according to my analysis, they are expressing that they don't understand some aspect of the thing in question, and they are requesting that it be made intelligible to them. Specifically, what they want is the sense of the event (which they are referring to as its 'meaning') and there at least five different kinds of answers we could provide. Which of these five answers or 'meanings' should be offered as the meaning of the event, will then depend on the concerns of the person asking the question, and which sub-question was most salient at the time of asking.

Nevertheless, it stands to reason that different individuals might offer different answers here, even to the same sub-question. This is because we can each perceive different meanings in the same thing depending on various factors, such as: what kind of information we have access to, our background beliefs, and our facility for reasoning and deduction. Indeed, these factors can have such an effect that different individuals may see the same event as having wildly contrasting meanings, or even perceive it as being entirely without meaning, while others see its meaning as obvious and unambiguous. For instance, when I reflect on lightning, this phenomenon will have an origin-meaning for me if I am aware of some minimally comprehensible causal explanation for it, and the content of this particular origin-meaning will depend on what I've observed, learned, or been told about lightning, say, that it is the result of electrically charged particles. ${ }^{20}$ Alternatively, if I come across someone who believes that lightning is caused by the god Thor, ${ }^{21}$ then for that person, lightning will have a very different origin-meaning.

\footnotetext{
${ }^{19}$ In this case the communicative-meaning would not be directly signified by the play, but still contained within it, as a fable can be said to contain a message or lesson to be learnt.

${ }^{20}$ If I've heard nothing about the origins of lightning, or only heard explanations which are, to me, unintelligible, then I won't perceive it as having any origin-meaning. Rather, it will seem to be a random and 'meaningless' occurrence. This intelligibility requirement follows naturally from the fact that gaining an understanding of some thing is precisely what meanings are for, so an alleged meaning which remains unintelligible to me will fail to count as a meaning at all.

21 Thank you to an anonymous reviewer for this nice example.
} 
What meanings something has will thus be relative to certain individuals, or rather certain groups of individuals who share the same mindset and beliefs about the world. That said, when we come across a conflict between meanings, we can do more than simply agree to disagree, as we might in a mere difference of taste. First of all, we could point out that the meaning a person perceives in something might be based on beliefs which are incorrect. We could also point out that someone's perceived meaning was based on biases, mistakes in reasoning, or other faulty thought-processes. If our interlocutors are not responsive to these observations, however, then there isn't much more we can do; it would remain true that for them (and others with the same perspective and beliefs), that event/phenomenon has that meaning.

Nevertheless, I take it that many of us do care whether the meanings we perceive in the world and in our lives are based on faulty assumptions or mistaken inferences. As evidence, being reliably informed that we have erred in some way can often cause us to update our perception of the meaning of some event or whether it even has a meaning in that regard. Granting this, there are certain perspectives which we may hope our own perspectives on meaning align with - perspectives which are, for instance, free from our own personal unjustified biases, knowledge-gaps, and other cognitive faults. For instance, we may hope that the meaning we perceive in something is the same meaning that would be perceived by a properly informed and clear-thinking human being. Although the perceptions of meaning linked to such a perspective would not constitute anything like 'objective meaning', 22 they would at least give us something to aim for in our debates about, and interest in, the 'genuine' meanings of things.

Now we know what it is for an event or phenomenon to have a meaning (for a particular person), and five kinds of meaning they can have, we can apply this analysis to life, both individually and collectively understood. It is possible to interpret both $a$ life and all life as internally complex events, which would give us origin, impact, and narrative-meaning, but it is also possible to interpret them as actions, either taken by some creator being in their choice to generate the life, or as the conglomerate action of all living humans/a single human across their lifetime. This would give us both purpose-meaning and communicative-meaning but each would be split into two parts, given there are now two sets of intentions that might be relevant in each case. For instance, God could have intended to do or communicate a particular thing by creating us, but we could also intend to do or communicate something very different with our existence.

Nevertheless, I will not bring this last communicative sort of meaning into my conceptions primarily because it strikes me that this kind of meaning, unlike the others, is simply not the sort of meaning which is usually at stake when we think about the meaning of life; it might be possible for our lives to have a meaning like this, but that is not what we are concerned with when in the midst of an existential crisis; and the claim that x's life had a meaning would never normally be interpreted as the claim that x's life was itself a kind of message.

Granting all this, the question 'What is the meaning of all human life?' could potentially receive five kinds of appropriate answer, depending on which non-

\footnotetext{
${ }^{22}$ In fact, 'objective meaning' would be an incoherent concept to the extent the qualifier 'objective' identifies something which exists entirely independently of any particular perspective, while perceptions of meaning are necessarily linked to the perspective of some (at least hypothetical) being reflecting on their world.
} 
understood aspects of life were most salient to the asker (see Table 1). It will then have a meaning (or meanings) if the relevant questions are amenable to intelligible answers, and lack meanings if they are not.

The table above lays out the variety of interpretations the traditional meaning question could receive. Nevertheless, as I see it, there are a few questions that usually seem closer to the surface in the traditional question: 1, 3a, and perhaps 2 . Alternatively, the questions which typically seem least salient would be $3 \mathrm{~b}$ and 4 , the former because we don't typically imagine that humanity is collectively committed to some shared purpose, and the latter presumably because we already know what sort of things go on within life, for the most part.

The equivalent table for the meanings of individual lives (Table 2) looks similar, and again I believe the forms of meaning which we are typically most concerned with are 1, 2 and 3a. However, particularly with regard to our own lives, we may also be more interested in the other two forms of meaning as well: $3 \mathrm{~b}$, because the likelihood of there being a single identifiable purpose is much higher when we're talking about just one person, rather than all humanity, and so it makes more sense to ask the question; and 4, because the more detailed stories of individual lives are of particular pragmatic and emotional interest to us.

I have now provided a characterisation of the concept of meaning in general and accounts of what it takes for a life, and all life, to have such a meaning or meanings. Meaning is sense, and thus the meanings of (a) life, if it has them, are its senses - the intelligible answers to certain salient questions we have which would allow us to better understand (the) life. That said, what one should offer as an answer to questions about the meaning of (a) life is determined by the specific concerns of the asker, and whether (a) life is ultimately perceived to have various meanings or not will be relative to different people and is determined by their knowledge, beliefs, and cognitive capacities.

Granting the above, we now know, in these discussions, what meaning means, and we also know what it takes for a life, and all life, to at least be perceived by us as having $a$ meaning. In the next section, I will use this analysis to outline an accompanying characterisation of meaningfulness and an account of which variables determine the meaningfulness of an individual's life.

\section{Meaningfulness as Sensefulness}

One might assume that 'having a meaning' and 'being meaningful' would describe lives in the same states. This is understandable given how close the terms seem to be,

Table 1 Interpretations of the question 'What is the meaning of all human life?'

Salient form of meaning/sense

1. Origin

2. Impact

3a. Purpose (creator's)

3b. Purpose (humanity's own)

4. Narrative

\section{Accompanying question}

What caused us to exist?

What will our existence result in?

Why where we created?

What aim are we collectively most committed to?

What is life/ What happens within life? 
Table 2 Interpretations of the question 'What is the meaning of x's life?'

Salient form of meaning/sense

1. Origin

2. Impact

3a. Purpose (creator's)

3b. Purpose (individual's own)

4. Narrative
Accompanying question

What caused $\mathrm{x}$ to exist?

What did $x$ 's existence result in?

Why was $\mathrm{x}$ created?

What aim was $\mathrm{x}$ most committed to?

What happened in x's life?

but it is wrong. Although it may be true that a life cannot be meaningful without having a meaning and cannot be entirely meaningless if it has a meaning, the two concepts are not identical. The most obvious difference between the two is that, intuitively, having a meaning seems to be a binary concept - a meaning is something your life either has or lacks (in each respect 1-4) - whereas the meaningfulness of a life appears to be a matter of degree. For instance, a life can be a little bit meaningful or very meaningful, and one life can be more meaningful than another. ${ }^{23}$ Thus, there could be two lives which both have $a$ meaning, but which have different levels of meaningfulness. As an example, imagine a heart surgeon alongside someone who devotes their life to looking after their pet cat. Intuitively we may feel that both individuals have a meaning in their lives, but the heart surgeon lives a far more meaningful life in the end. It's clear that meaninghaving and meaningfulness are not identical then.

One way of understanding this according to my earlier analysis might be to suggest that people can have a meaning in their lives simply if they have a meaning in any one of the five senses proposed, but to have a meaning ful life, they must possess all five kinds of meaning. This is not what I mean to say. Instead, I think meaning-having and meaningfulness can be separated even within one category of meaning. For instance, in terms of the impact-meaning of the heart surgeon and cat-owner above; both individuals produce some concrete effect on the world, and so both individuals have an impact-meaning, but the heart surgeon's life seems to be more meaningful, even limited to just this respect. In fact, we might say the impact-meaning of the surgeon's life is itself a more meaningful meaning than the cat-owner's impact-meaning.

How can we explain this? What makes a meaning of an event or life more or less meaningful itself? Fortunately, we already have all the tools we need to answer this question; if the meaning of an event is simply its 'sense', then the meaningfulness of that information/meaning is simply its 'sensefulness' or how 'full-of-sense' it is. Naturally, an answer to one of the meaning-questions will be more senseful the more intelligible it is; however, by 'sensefulness' I mean to measure not just the degree to which the content of a particular meaning is intelligible but also the richness of that content. In psychological terms, 'meaningfulness' measures not just intelligibility but also the robustness and amount of individual meaning-connections associated with something or concentrated in some area of our meaning-framework. This means there is both a qualitative and quantitative aspect to sensefulness; even if an answer is totally intelligible, if it has very little or very weakly-connected content, it will be perceived as

\footnotetext{
${ }^{23}$ E.g. Metz (2013, p.6).
} 
less full-of-sense overall than an answer which is equally intelligible but involves a great deal more content or more robustly-connected content. Both answers will make sense to us in that we can comprehend them equally well, but the latter will have more sense in it - it will be more senseful - given the material there for us to comprehend is richer. To make an analogy, a single sentence and an entire book can be equally comprehensible, and thus both will have an equal quality of sense, but the book will have a larger quantity of sense (i.e. it will be more full-of-sense and meaning-full) than the sentence, given there are more ideas/claims/descriptions etc. in the book for us to make sense of.

Having outlined my proposal that the meaningfulness of something can be interpreted as it's sensefulness - i.e. the richness (robustness and quantity) of its content, multiplied by how intelligible that content is - we can now outline some of the ways any event can be meaningful, corresponding to some of the ways any event can have a meaning ${ }^{24}$ :

1. Origin-meaning: 'What caused $\mathrm{x}$ to happen?' The sensefulness or meaningfulness of the answer to this question will be a measure of how many entities, forces, events etc. conspired to produce $\mathrm{x}$, multiplied by the comprehensibility and strength of this causal web. Like other meanings, the origin-meaning of a thing can operate on a higher-order level, being built out of a multitude of smaller interconnected meanings, and the more of these meanings there are, and the more robust they are, (assuming they can all be grasped and coherently connected to our wider meaning-framework), the more meaningful/senseful that origin-meaning will be. Thus, an event which was the culmination of centuries of planning and work by thousands of different people and organisations is going to be more meaningful than an event which was merely caused by the passing whim of an individual person, or a gust of wind. This evaluation strikes me as intuitively plausible and hence the example supports my proposed concept of meaningfulness; although the explanations of each event are equally intelligible, the explanation of the former event will be simply richer and more brimming with meaning-connections than the latter explanation, which means it will be more full-of-sense.

2. Impact-meaning: 'What resulted from $\mathrm{x}$ ?' The sensefulness or meaningfulness of answers to this question are determined in essentially the same way as the first but mirrored so as to look into the future following the event, rather than the past leading up to it. An event will be more senseful in this respect to the extent the answer to the above question is both intelligible and rich in terms of touching many people, places, things etc. and affecting them in a powerful rather than weak way; i.e. if the impact-meaning itself involves more (and more robust) internal meaningconnections. Again, I think this sits perfectly with our intuitions. A cure for cancer would have a more meaningful effect on the world than a cure for some less pervasive disease, since the effects of the former go further and involve more people and to a greater degree.

3. Purpose-meaning: 'Why was x performed?' The answer to this question - this kind of meaning - was an account of the intentions of the agent who chose or carried out

\footnotetext{
${ }^{24}$ Here I ignore the communicative variety of meaningfulness again, as it remains irrelevant to my ultimate concern of (a) life's meaningfulness.
} 
the action, provided those intentions were minimally coherent; if the agent's intentions were nonsense, however, then we would say their action had no meaning. Nevertheless, as above, the sensefulness of an action is determined by additional variables: not just the degree to which the intended purpose is coherent (e.g. logically or practically achievable), but also the complexity of the individual's plan and the strength or deliberateness of their intentions (i.e. the robustness of the relevant meaning-connections). The sensefulness or meaningfulness of an activity in this form is thus a measure of the intricacy or scope of the activity and the extent to which the purposes motivating it were both intelligible and strongly-held. Accordingly, someone who wholeheartedly devoted his day to building a boat will have been acting more meaningfully, or with more sense to his actions, than someone who half-heartedly did the same, or someone who wholeheartedly spent their day trying to draw a square circle.

4. Narrative-meaning: 'What was the story of $x$ ?' Once again, the meaning of an event or sequence of events, in this sense, is the minimally comprehensible story that can be told of them. However, this story will be more meaningful the richer it gets - involving more characters, projects, achievements - and the more intelligible its connections and plotlines. The problem here - which also exists for the other varieties of meaningfulness, to some extent - is that the complexity or richness of the story and its intelligibility cannot both be maximised at the same time, since the more content or meaning-connections that fill a story, the harder it will be for us to comprehend. Thus, the ideally meaningful life, in this sense, will be a life that involves a healthy and varied amount of content and yet has a plot which is stable and coherent enough for us to follow. ${ }^{25}$ Once more this chimes with our intuitions; both someone who lives an essentially empty life with no friends or projects, and someone who lives a chaotically and incomprehensibly busy life, seem to have less meaningful life-stories than a person whose life is rich and intelligible, perhaps following a familiar pattern of long-term efforts overcoming obstacles and leading to lasting success.

Returning to the analysis of the last section, we can identify five aspects of (a) life which can be assessed for their meaningfulness, corresponding to the five kinds of meaning it could have: its 1. Origin, 2. Impact, 3a. Purpose (our creator's), 3b. Purpose (our own), and 4. Narrative. This means that, an individual's life, for instance, will have high levels of meaningfulness if it was the product of the confluence of several identifiable forces and entities (1), which worked over centuries to deliberately create them for some comprehensible purpose (3a), and if it involved a rich and intelligible life-story (4) of passionate and coherent pursuits ( $3 b$ ) and led to massively significant impacts (2). Whilst an individual's life will have the lowest levels of meaningfulness when it was a product of a single random and non-agential cause, and they led an empty or utterly confusing life-story and died leaving no trace of them ever having existed.

Similar archetypically meaningful and meaningless forms can be applied to human life itself; i.e. life would be more meaningful if we existed for a reason, and left a big

\footnotetext{
${ }^{25}$ On a similar note, Kauppinen also points out the problems for meaningfulness that are caused by having too much or not enough variety in one's life, and ultimately suggests an ideally meaningful life-story would involve a variety of activities coherently linked together (2012, p.365-8).
} 
impact on the universe, and so on. However, I think we should resist the temptation to aggregate all the forms of meaningfulness into one overall score like this because meaningfulness does not necessarily function that way; in a similar way to meaning, the aspects of (a) life which determine its overall meaningfulness will be a relational fact, depending again on the concerns of the person performing the assessment. For someone who cares only about significance, a person with a perfect life story, who nevertheless leaves no trace, will have a meaningless life overall. On the other hand, for a person who cares most about why we are here, a life will seem fairly meaningful if God deliberately created it, no matter how aimless or empty it ultimately turned out to be. In all cases though, when (a) life seems meaningful, it will be because it had a meaning or meanings which struck us as rich and comprehensible, and where (a) life seems meaningless it will either be because the meanings we were concerned about were relatively empty of content, or the content those meanings did have was weak or incoherent (i.e. they lacked sense in terms of quality).

\section{Advantages of the Sense/Sensefulness Account}

Having laid out my full analysis of meaning and meaningfulness, it is now time to outline the strengths of my account and the ways in which it compares favourably to competing theories in the literature. First of all, it is a more comprehensive account than most provided so far. As noted, most theorists simply address themselves to answering either the question 'What makes a life meaningful' or, less commonly, 'What is the meaning of life?', but neglect to broaden their accounts or try to indicate how the two topics could be related. On the other hand, my account provides characterisations of both meaningfulness and meaning which fit together and give way to sets of relatively concrete application conditions for each. Furthermore, as Kauppinen has pointed out (2012, p.352), the vast majority of existing theories merely lay out the criteria or requirements for a life to count as meaningful, without saying anything about what meaningfulness actually means, as I have done. In other words, they provide conceptions of meaningfulness but say nothing about the concept they are providing conceptions of. ${ }^{26}$

Moreover, my identification of 'meaning' with 'sense' aligns with a natural everyday use of the term 'meaning'. This is particularly clear when we note the similarities between the questions 'What is the meaning of life?' and 'What is the meaning of this?', the latter of which transparently takes 'meaning' to mean 'sense'. My account also enjoys a great deal of support from psychological theory and experimental studies, and from the many translations of the phrase 'meaning of life', which demonstrate the centrality of 'sense' in the concept. Additionally, my theory chimes with our intuitions about when a life will have or lack a particular meaning and what kind of answers might be appropriate to the question 'What is the meaning of X?' As I have shown in section 3, the meanings of a life are the answers to various kinds of question that might be asked in order to better make sense of it. If a life is not perceived as having an

\footnotetext{
${ }^{26}$ Kauppinen (2012), Metz (2013), and Martela (2017) make this distinction using these terms and, notably, each say something about the concept of meaningfulness their theory employs. Fischer $(2005,2009)$ also attempts to do this, although he does not use the language of concepts and conceptions.
} 
intelligible cause, effect, purpose, or story, then we will naturally say it has no meaning in these senses. Yet, if it does have these things, then giving any one of them can sometimes be an appropriate response to the question at hand. In other words, if asked for the meaning of X's life, depending on the context, it could be entirely fitting to reply either with information about where X came from, what X's life led to, what purpose X was chiefly involved in pursuing, or what the story of X's life was.

The fact that several sorts of answers can legitimately be seen as a type of meaning, and consequently, several variables can be seen as determining the meaningfulness of a life, also stands as an advantage over most of the existing theories of meaningfulness proposed in the literature. For instance, 'consequentialist' theories, such as those of Smuts (2013) or Bramble (2015), suggest that a life will be meaningful to the extent that it produces value or makes the world a better place. If I am right, then these theories will have successfully identified something close to one key factor relevant to the meaningfulness of a life - its impact - but such theories neglect all other relevant factors, to their detriment. For instance, we can see that the short life of someone with unique DNA unwillingly tortured for medical data must be lacking in at least some kinds of meaningfulness, no matter how significant and valuable the results were.

In line with such observations, Purves and Delon (2018) have noted that such consequentialist theories are implausible because they fail to take into account whether the individual's life involved any intentional actions or deliberate work. Here, it seems that they have correctly identified the bearing of purpose to the meaningfulness of a life. Yet, Purves and Delon, along with theorists such as Luper (2014), Bradford (2015), and Levy (2005), whose theories also champion the relevance of purposeful action or pursuit of one's goals, are also too narrow. They perhaps indicate when a life is likely to have both the purpose (3b) and impact (2) varieties of meaningfulness, but they themselves neglect other varieties of meaningfulness such as narrative (4) or originmeaning (1). Many other accounts also fall into this category of theories which appear to involve both valuable effects and some kind of intentional effort towards them, such as Nozick's (2001) 'connecting to or promoting organic unity', or Metz' (2013) 'directing one's rationality toward the fundamental conditions of human existence'. However, they too fall foul of being overly narrow, and neglecting other variables which also matter.

Narrativist theories are typically the most promising, such as those of Fischer (2005, 2009) and Kauppinen (2012), as they appear to incorporate some measure of the coherence or comprehensibility of the individual's life-story as well as elements of purposefulness and significance (with these elements made explicitly clear in Kauppinen's theory in particular). Nevertheless, even these theories neglect to acknowledge that having been created with a purpose in mind (instead of merely adopting one) or having an intelligible causal explanation for our lives can also be relevant in determining their meaningfulness. Moreover, Fischer and Kauppinen each characterise the concept or meaning of meaningfulness itself in ways that appear less plausible than my own proposal. Fischer, for instance, identifies meaningfulness as "the value of artistic creativity or self-expression" (2005, p.379), while Kauppinen characterises it as condition of a life for which pride, admiration, or fulfilment would be fitting (2012, p.353). Yet, neither of these concepts align with anything like an everyday use of the term 'meaningful'. Furthermore, neither of these concepts align very well with our intuitions about what existential meaningfulness $i s$; a person who complained that their 
life involved no self-expression and would be inappropriate as an object of admiration or fulfilment might also have had a meaningless existence, but this appears to be saying something different or over-and-above the admission that they've merely lived uncreatively and wasted their time.

On the other hand, as noted, my own interpretation of meaningfulness as 'sensefulness' does have some connection to our everyday language and succeeds in aligning with our strongest intuitions about when (a) life will be meaningful (and meaningless), to what degree, and for what reasons. For instance, a life does indeed seem more meaningful to the extent it has a substantial and coherent impact on the world. Moreover, while I previously asserted that the unwilling subject of medical experiments would not seem to have an ideally meaningful life, regardless of how significant the results were, this is not a problem for my theory granting, as it does, that impact is just one of several types of meaningfulness we can be concerned with, and the individual in question will presumably have a weak life-story (4) and be lacking in strong commitment to any aim (3b). ${ }^{27}$ A person's life will also typically strike us as more meaningful the more richly coherent their life-story is, and the more richly intelligible their origins and purposes are.

Additionally, my account can explain why the 'death of god' led to feelings of meaninglessness for many ${ }^{28}$ : absent God's intentions in creating us, life lost its assigned purpose and hence one of its varieties of meaning and meaningfulness (3a). ${ }^{29}$ Similarly, my account can clarify precisely what was going on in John Stuart Mill's worry that achieving his life's goals would actually constitute a crisis of meaning for him, ${ }^{30}$ since he would be trading added impact (2) for a loss of purpose in life (3b), and an emptier life-story (4). Moreover, it also explains why our existence seems less meaningful when we chalk it up to random chance, but more meaningful when we cast it as the pinnacle of millions of years of evolution, since this explanation of our origin strikes us as richer and more coherent (1). Finally, only by conceiving of meaningfulness as sensefulness can we explain why absurdity - incoherence, irrationality, or nonsense (Feinberg 1992, p.156) - is treated by so many as connected to meaninglessness ${ }^{31}$ which other theorists, who understand meaningfulness differently, are forced to deny. ${ }^{32}$

What about subjectivist or hybrid theories of meaningfulness though? These are accounts which hold that, in order for a person's life to be truly meaningful, they must also possess the right sort of positive attitude or appraisal of their life. For instance, simple subjectivist accounts, such as Richard Taylor's fulfilment theory (1970) and Harry Frankfurt's loving/caring theory (1988) typically hold that an activity causing a certain attitude or feeling in the individual (e.g. fulfilment or love) is both necessary and sufficient to render it meaningful. More advanced subjectivist accounts hold that we are

\footnotetext{
${ }^{27}$ Of course, if they deliberately volunteered for the experiments these claims would be less true, but then I think the life would accordingly seem that much more meaningful.

${ }^{28}$ For instance, Baggini writes: "All would agree that the 'discovery' that there is no God has created a crisis of meaning for human life" (2005, p.10).

${ }^{29}$ Landau (1997, p.265) makes something like this point. Similarly, George and Park point out that religious belief could allow one to give additional (purpose) meaning to periods of trauma and suffering within life, which the non-religious might not have access to (2016, p.207).

${ }^{30}$ Mill wrote about this crisis in his (1924) autobiography and it is often discussed in the literature, e.g. Bradford (2015) and Levy (2005).

${ }^{31}$ For instance, Camus (1942) and Nagel (1971).

${ }^{32}$ For instance, Metz (2013, p.6) and Brill (2007, p.6).
} 
living meaningfully if and only if we are engaged in activities which we value or take ourselves, in our best judgement, to have good reason to value (e.g. Calhoun 2018). ${ }^{33}$ Alternatively, hybrid theories suggest that this sort of subjective appreciation or valuation is not sufficient for meaningfulness, but is still necessary. For instance, Wolf has proposed that meaningfulness is generated when a life involves both the production of objective value and subjective fulfilment (2010), and Evers and van Smeden argue the same but substitute a notion of 'valuation' for fulfilment (2016).

If subjective fulfilment or mere positive valuation of one's life were always sufficient for meaningfulness, then my own account will be mistaken. Nevertheless, granting such a premise leads to some unacceptable false-positives. For instance, in the case of the simple subjectivist conceptions, it seems that we could end up with a meaningful life simply by plugging ourselves into an experience machine (Nozick 1974, p.42), or taking a special pill (Brogaard and Smith 2005, p445) and most, I presume, would reject these suggestions as absurd. ${ }^{34}$ The more advanced subjectivist theories - which require us to actually engage with projects which we value - avoid the above problems, but still seem vulnerable to the objection that one could live a meaningful life by watching paint dry, provided one had come to value this activity in the right way. Theorists here sometimes note that it would be incredibly unlikely for any psychologically normal human to sincerely value this sort of thing ${ }^{35}$ - but to the extent it is theoretically conceivable, it remains a fairly damning problem.

Finding value or fulfilment in one's activities cannot be sufficient for a meaningful life then, but could it be a necessary condition? This requirement seems more plausible. It would also be relatively easy to incorporate it into my own account. Specifically, instead of claiming that a life will be meaningful (in various ways), to the extent we perceive it as having some rich and intelligible origin, impact, purpose, or story, I would also have to stipulate that one's life will count as meaningful only when it has such features and they are positively appraised in some regard. For example, it would not be enough to merely produce some large impact on the world, that impact would have to be seen as positive in order to confer any meaningfulness on one's life.

One reason for supporting such a value-condition is that many people take meaningfulness to be closely connected to whether life is worthwhile. ${ }^{36}$ The descriptor 'meaningful' is commonly applied to things seemingly in virtue of their worth, especially in reference to a person's life, where 'meaningfulness' is often taken explicitly to denote a kind of final value - a quality of life which it is necessarily good for the individual to possess. ${ }^{37}$ Indeed, it is true that a meaningful life, even understood

\footnotetext{
${ }^{33}$ A third potential variety of subjectivist theory might say that a person's life is meaningful if and only if they themselves feel a sense of meaningfulness in regard to it. If we interpret this feeling of meaningfulness as a feeling associated with the perception of sense (as Heintzelman and King suggest [2014, p.163]), then this theory will not be far from my own account. Nevertheless, even if a person experiences their own life as meaningful, others might not judge it the same way (e.g. if they find it unintelligible), so we might prefer to qualify that a person's life will be meaningful for them, to the extent they experience this feeling.

${ }^{34}$ Moreover, psychological work has demonstrated that feelings of "meaning in life can exist in the absence of positive affect" and vice versa (Heintzelman and King 2014, p.163).

${ }^{35}$ E.g. Calhoun (2018, p.41-2), Arpaly (2010, p.87), and Kekes (1986, p.85-86).

${ }^{36}$ Camus (1942), for instance, famously wrote that the meaning of life was the most important philosophical question because it determined whether or not life was worth living.

${ }^{37}$ For instance, Metz (2013, p.4), Wolf (2010, p.8), and Smuts (2013, p.538). See Thomas (2018) for a critique of this assumption.
} 
value-neutrally, is something that almost all of us will want. We want our existence to be richly comprehensible; we want a life with a graspable life-story, and with origins, aims, and effects that make sense to us. Yet, the admission that a meaningful life will often be good for us does not entail the content of a life's meanings must themselves be seen as positive or valuable; meaningfulness can be an object of desire even if it is merely a value-neutral measure of richness and comprehensibility.

The assumption that a life can only be meaningful through involvement in positively-valued features is not outlandish, however. For instance, there will typically be a large overlap between lives which we perceive as worthwhile or valuable, and lives which fulfil my various value-neutral conditions for meaningfulness: e.g. lives successfully devoted to some noble cause will also possess a high degree of purpose and impact-meaningfulness. Moreover, it would be difficult for us to evaluate a life positively without it being basically comprehensible (Martela and Steger 2016, p.538). Thus, the presence of some kind of positive value is often sufficient for meaningfulness even on my account, and meaningfulness (or basic intelligibility at least) may be necessary for some kind of positive valuation. Given this, it would not be surprising to discover the two concepts had become entangled, leaving people with the impression that value or worthiness was a necessary aspect of meaningfulness itself. Nevertheless, I reject this suggestion: events and lives can be meaningful without being worthy or producing positive value. Indeed, when we think of meaningful events, the examples which first come to mind are often those with incredibly negative value, such as WWII or 9/11 (Bradford 2015, p.5).

The absence of any value condition in my account might be objected to on a couple of grounds. First, one might argue that it entails two people with outwardly identical lives will have identical levels of meaningfulness even if one loved their time on Earth while the other found their life miserable and worthless. This is not so: to the extent meaningfulness requires the various features of a person's life to be comprehensible, the latter person will have a less meaningful life, granting that it makes less sense to lead a life one finds no worth in. My theory does imply that such a miserable person could have a somewhat meaningful life, but that strikes me as entirely appropriate. Contra hybrid theorists like Wolf, someone like Martin Luther King would still seem to have a substantially meaningful life, even if he saw no value in his work but was rather motivated by mere compulsion.

Another consequence of value-neutral theories like my own is that they entail individuals like Hitler could have had meaningful lives, which is unpalatable for many. ${ }^{38}$ Nevertheless, some theorists have bitten this bullet and argued that Hitler's life really was meaningful, ${ }^{39}$ and I am willing to bite this bullet too. Hitler's life certainly had several high levels of meaningfulness in virtue of his dedication to his purpose (3b), the generally rich and coherent story of his life as he overcame obstacles in his rise to power (4), and in the massive impact he had on the entire world (2). ${ }^{40}$ Nevertheless, I think we can stomach this conclusion if we remind ourselves that

\footnotetext{
$\overline{38}$ For instance, Martela (2017, p.252) and Kauppinen (2012, p.361, footnote 31) both specifically deny that Hitler could have lived a meaningful life, and others such as Bramble (2015), Smuts (2012), and Wolf (2010) would all likely say the same, given that their theories each involve an explicit objective value requirement.

${ }^{39}$ For instance, Kekes (2000, p.30), Baggini (2005, p.175), and Wong (2008, p.142)

${ }^{40}$ That said, there is certainly room to criticise the coherence of certain aspects of his life, such as his overall aims, and this would negatively affect the meaningfulness of his life.
} 
evaluating a life as meaningful is not necessarily to praise it, at least, not according to my analysis. Thus, while Hitler's life was hugely evil in many ways, it would be wrong to deny it was meaningful, just as it would be wrong to deny, for instance, that he was a famous figure; like meaningfulness, this is not inherently a form of commendation. ${ }^{41}$ Moreover, while we might all desire a meaningful life, getting a meaningful life is not the only thing that matters to us. Specifically, what we presumably desire is for our lives to be meaningful and good, or perhaps meaningful for the right reasons.

I have rejected the need to introduce a value-requirement into my theory as either a sufficient or necessary condition for meaningfulness tout court. Nevertheless, there is perhaps a weaker way value could be incorporated: I could simply add value-meaning as another kind of meaning alongside origin-meaning, impact-meaning etc. Something's value-meaning would constitute the answer to the question: 'What is valuable about it?' and a life or event would be more value-meaning ful the more valuable it was. Positive evaluation would be both necessary and sufficient for value-meaning then, but the other kinds of meaning would remain value-neutral. Whether this final adjustment would please the subjectivists/hybridists will depend on their motivations for thinking value is relevant: for instance, it would not allow us to deny Hitler's life was meaningful in any way, but it would allow us to point to one way a valuable/worthwhile life is, ceteris paribus, more meaningful than a worthless one. In the end, I do not believe that my theory needs value-meaning to be complete, but it is certainly capable of accepting this addition if it constitutes an improvement.

To conclude, I have presented and defended a complete and unified theory of meaning and meaningfulness, which resonates with our strongest and most plausible intuitions about what variables are relevant to meaning in life and what this topic is really about. This analysis has strong linguistic, philosophical, and psychological support, and succeeds in simultaneously incorporating the insights of the best existing theories whilst avoiding the problems inherent in those overly narrow accounts. Granting all I have argued, we have several very good reasons to believe that, when we say we want our lives to have a meaning, what we are really saying is that we want them to have an intelligible origin, impact, purpose, or story, and when we say we want them to be meaningful, what we are really saying is that we want them to be both rich and intelligible in one or more of these respects - in other words, we want them to be full of sense.

OpenAccess This article is distributed under the terms of the Creative Commons Attribution 4.0 International License (http://creativecommons.org/licenses/by/4.0/), which permits unrestricted use, distribution, and reproduction in any medium, provided you give appropriate credit to the original author(s) and the source, provide a link to the Creative Commons license, and indicate if changes were made.

Publisher's Note Springer Nature remains neutral with regard to jurisdictional claims in published maps and institutional affiliations.

\footnotetext{
${ }^{41}$ People are perhaps more willing to apply meaningfulness in a value-neutral way to things like WWII and 9/11 given the focus is on the event, and so they are less likely to interpreted as praising any particular wrongdoer.
} 


\section{References}

Arpaly, N. (2010). Comment. In S. Wolf (Ed.), Meaning in life and why it matters (pp. 85-91). Princeton: Princeton University Press.

Audi, R. (2005). Intrinsic value and meaningful life. Philosophical Papers, 34(3), 331-355.

Baggini, J. (2005). What's it all about? Philosophy and the meaning of life. London: Granta Books.

Bennett, J. O. (1984). The meaning of life: A qualitative perspective. Canadian Journal of Philosophy, 14(4), 581-592.

Bradford, G. (2015). Achievement and the Meaning of Life, URL= http://bradford.rice.edu/research/. Accessed 23 Feb 2017.

Bramble, B. (2015). Consequentialism about meaning in life. Utilitas, 27(4), 445-459.

Brill, S. (2007). Does it matter that nothing we do will matter in a million years? Dialogue, 46, 3-25.

Brogaard, B., \& Smith, B. (2005). On luck, responsibility, and the meaning of life. Philosophical Papers, 34, $443-458$.

Calhoun, C. (2018). Doing valuable time: The present, the future, and meaningful living. Oxford: Oxford University Press.

Camus, A. (1942). The myth of Sisyphus (trans: O'Brien, J., (2000)). Penguin Classics, London.

Cottingham, J. (2003). On the meaning of life. London: Routledge.

Evers, D., \& van Smeden, G. E. (2016). Meaning in life: In defense of the hybrid view. The Southern Journal of Philosophy, 54(3), 355-371.

Feinberg, J. (1992). Absurd self-fulfilment. In Klemke (Ed.), The meaning of life (Vol. 2000, pp. 153-183). Oxford: Oxford University Press.

Fischer, J. M. (2005). Free will, death, and immortality: The role of narrative. Philosophical Papers, 34(3), 379-403.

Fischer, J. M. (2009). Our stories. Essays on life, death, and free will. Oxford: Oxford University Press.

Frankfurt, H. (1988). The importance of what we care about. New York: Cambridge University Press.

Frankl, V. E. (1946). Man's search for meaning: An introduction to logotherap Translated by Ilse Lasch, 1964, Hodder and Stoughton Ltd.

George, L. S., \& Park, C. L. (2016). Meaning in life as comprehension, purpose, and mattering: Toward integration and new research questions. Review of General Psychology, 20(3), 205-220.

Grice, H. P. (1957). Meaning. The Philosophical Review, 66(3), 377-388.

Heine, S. J., Proulx, T., \& Vohs, K. D. (2006). The meaning maintenance model: On the coherence of human motivations. Personality and Social Psychology Review, 10, 88-110.

Heintzelman, S. J., \& King, L. A. (2014). (The feeling of) meaning-as-information. Personality and Social Psychology Review, 18(2), 153-167.

Heintzelman, S. J., Trent, J., \& King, L. A. (2013). Encounters with objective coherence and the experience of meaning in life. Psychological Science, 24(6), 991-998.

Heyd, D., \& Miller, F. G. (2010). Life plans: Do they give meaning to our lives? The Monist, 93(1), 17-37.

Hicks, J. A., \& Routledge, C. (2013). The experience of meaning in life: Classical perspectives, emerging themes, and controversies. Berlin: Springer.

Juhl, Jacob and Routledge, Clay, (2013), "Nostalgia bolsters perceptions of a meaningful self in a meaningful world", in Joshua A. Hicks, Clay Routledge, (eds.), The experience of meaning in life: Classical perspectives, emerging themes, and controversies, Springer, Berlin, pp. 213-226.

Kauppinen, A. (2012). Meaningfulness and time. Philosophy and Phenomenological Research, 82, 345-377.

Kekes, J. (1986). The informed will and the meaning of life. Philosophy and Phenomenological Research, 47, 75-90.

Kekes, J. (2000). The meaning of life. In P. French \& H. Wettstein (Eds.), Life and death: Metaphysics and ethics (Midwest Studies in Philosophy) (Vol. 24, pp. 17-34).

Landau, I. (1997). Why has the question of the meaning of life arisen in the last two and a half centuries? Philosophy Today, 41(2), 263-269.

Levy, N. (2005). Downshifting and meaning in life. Ratio, 18, 176-189.

Luper, S. (2014). Life's meaning. In S. Luper (Ed.), Life and death (pp. 198-212). Cambridge: Cambridge University Press.

Markman, K. D., Proulx, T., \& Lindberg, M. J. (Eds.). (2013). The psychology of meaning. Washington D.C.: American Psychological Association.

Martela, F. (2017). Meaningfulness as contribution. The Southern Journal of Philosophy, 55(2), 232-256.

Martela, F., \& Steger, M. F. (2016). The three meanings of meaning in life: Distinguishing coherence, purpose, and significance. The Journal of Positive Psychology, 11(5), 531-545. 
Metz, T. (2013). Meaning in life: An analytic study. Oxford: Oxford University Press.

Nagel, T. (1971). The absurd. The Journal of Philosophy, Vol. 68, No. 20, Sixty-Eighth Annual Meeting of the American Philosophical Association Eastern Division, pp. 716-727.

Nozick, R. (1974). Anarchy, state, and utopia. New York: Basic Books.

Nozick, R. (2001). Philosophical explanations. Cambridge: Harvard University Press.

Proulx, T., \& Heine, S. J. (2006). Death and black diamonds: Meaning, mortality, and the meaning maintenance model. Psychological Inquiry, 17(4), 309-318.

Proulx, T., \& Heine, S. J. (2009). Connections from Kafka: Exposure to meaning threats improves implicit learning of an artificial grammar. Psychological Science, 20(9), 1125-1131.

Purves, D., \& Delon, N. (2018). Meaning in the lives of humans and other animals. Philosophical Studies, 175(2), 317-338.

Schinkel, A., Ruyter, D. J., \& Aviram, A. (2015). Education and life's meaning. Journal of Philosophy of Education, 50(2).

Seachris, J. W. (2009). The meaning of life as narrative: A new proposal for interpreting Philosophy's 'primary' question. Philo, 12, 5-23.

Smuts, A. (2013). The good cause account of the meaning of life. The Southern Journal of Philosophy, 51(4), $536-562$.

Stillman, T. F., \& Lambert, N. M. (2013). The bidirectional relationship of meaning and belonging. In J. A. Hicks \& C. Routledge (Eds.), The experience of meaning in life: Classical perspectives, emerging themes, and controversies (pp. 305-315). Berlin: Springer.

Strawson, G. (2004). Against Narrativity. Ratio, 17(4), 428-452.

Tartaglia, J. (2015). Metz's quest for the holy grail. Journal of Philosophy of Life, 5(3), 90-111.

Tartaglia, J. (2016). Is philosophy all about the meaning of life? Metaphilosophy, 47(2), 283-303.

Taylor, R. (1970). The meaning of life. In D. Benatar (Ed.), Life death and meaning, Rowman and Littlefield publishers, (2004) (pp. 19-28).

Thomas, J. L. (2018). Can only human lives be meaningful? Philosophical Papers, 47(2), 265-297.

Thomson, G. (2003). On the meaning of life. In Thomson learning.

Veal, D. (2017). "'Life is meaningless.' compared to what?". Journal of Philosophy of Life, 7(1), 208-260.

Velleman, J. D. (2003). Narrative explanation. Philosophical Review, 112(1), 1-25.

Vice, S. (2003). Literature and the narrative self. Philosophy, 78(1), 93-108.

White, J. (2009). "Education and a meaningful life". Oxford Review of Education, 35(4), 423-435.

Wolf, S. (2010). Meaning in life and why it matters. Princeton: Princeton University Press.

Wong, W.-H. (2008). Meaningfulness and identities. Ethical Theory and Moral Practice, 11(2), 123-148. 